\title{
Village Cadre Competency and Rural Development: A Literature Review
}

\author{
Hui Liu \\ International Business School, Shaanxi Normal University, Xi'an, Shaanxi, China, 710062, \\ 346591653@163.com
}

Keywords: competency, rural cadres, rural development

\begin{abstract}
Rural development is affected by many factors, among which the influence of village cadres is also very important. Many studies have indicated that the village cadres played a significant role in the social, political and economic development of the rural areas. The village cadre is the leader for becoming rich, the spreader of farming techniques and the maintainer of rural social stability. The sense of responsibility and the working capabilities of village cadres have a direct impact on the development of rural areas. From the perspective of competency, this paper analyzes and evaluates the main views of village cadre competency and rural development to further clarify the present research situation and the future research trends, which provides a reference for the modes by which endogenetic power can be utilized to change the backward conditions prevalent in the rural areas of China.
\end{abstract}

\section{Introduction}

"Issues of agriculture, rural areas and farmers" have been the most important task for Chinese government. Village cadres are the leaders of the villagers and the key endogenetic power to promote the rural economic growth and the rural social development. From the perspective of competency, this paper analyzes and evaluates the main views of village cadre competency and rural development to further clarify the present research situation and the future research trends, which provides a reference for the modes by which endogenetic power can be utilized to change the backward conditions prevalent in the rural areas of China.

\section{Research of Competency of Village Cadres}

\subsection{Connotation of Competency}

Research of competency can be traced back to the scientific management movement of Tailor (1911); through the analysis method of 'time-action', he studied the difference between excellent workers and common worker. In 1973, McClelland, the professor of Harvard University and famous psychologist issued a paper titled 'Testing for Competence rather than Intelligence' on American Psychologist and formally proposed the concept of 'competency'. He held that the traditional test method, such as intelligence test and academic test could not well predict the achievements of work or success in life; but competency could. 'Competency is the knowledge, skill, ability, specialty or motive similar or related to work achievements or other important achievements in life'. Issue of this paper marks the beginning of Competency Movement. Since then, many scholars began to pay attention to research of competence; however, there has not been a unified definition of competency, so different scholars proposed their understandings of competency from different perspectives. For a long time, scholars hold three different viewpoints concerning the connotation of competency: characteristics outlook, behavior outlook and comprehensive outlook. Scholars of characteristics outlook hold that competency is the during, intrinsic or extrinsic individual characteristics, namely what is human being. Such individual 
characteristic varies between people with excellent achievements and people with common achievements (Boyatzis 1982, Spencer 1993).

Scholars of 'behavior outlook' hold that competency is a kind of behavior related to individual; namely, it is what man has done on its post and is the concrete application and actual behavior of their knowledge, skill and motives under specific conditions. The representative scholars are Woodruff and Fletcher etc. These scholars hold that competency is the concrete behavior of the excellent achievements and is the concrete application of knowledge, skill, attitude and motive under specific conditions; it can be observed and measured. To assess the competency of people from their extrinsic behaviors is good for accurate understanding and unified recognition of competency (Li Mingfei, 2004), but it is easily mistaken with behavior performance.

Through the above summary of the concept of competency, it is seen that the statement related to competency is not unified. Through in-depth analysis, the main characteristics of competency are shown in the following three aspects: first, pertinence of work post--competency of different work posts is different; second, pertinence of work achievements--high competency can predict higher work achievements; third, competency can be gained through observation and measure of individual behaviors.

\subsection{Application Research of Competency Model}

Competency model is the sum of knowledge, skill, ability and attitude of people with excellent achievements in a post/career; it is the collection of characteristics of competency. The main contents of constructing competency model is to recognize the characteristics of competency. The behavior event interview method first adopted by McClelland in order to choose the overseas liaison officer for American government is widely regarded by scholars to be effective in recognizing elements of competency. Domestic and foreign scholars have adopted multiple research methods and have proposed the competency models suitable for enterprises, public education and administrative management of government. These competency models have played important roles in recruitment and election, training, performance assessment and salary management of human resource management.

Since the beginning of 2000, many domestic scholars have carried out research of application of competency models. Scholars Wang Chongming and Chen Minke (2002) took 220 middle-level and high-level managers from 51 enterprises as the research objects and constructed the competency model of principal and deputy managers. Wei Jun and Zhang De (2005) adopted the behavior event method and focus interview method; through investigation of large sample bank client managers, they constructed six-dimensional competency model of bank client manager: mastery of information, expansion demonstration, relational management, self-motivation, consultation, negotiation and communication. In recent years, application research of competency model has been applied to more industries and fields (Liu Guosheng 2009, Chen Yansong 2010 and Liu Wenkai 2011).

\subsection{Related Research of Competency of Village Cadres}

Competency qualities of village cadres and the related issues of team construction of village cadres have attracted the attention of many scholars; most of the researches have been done from the qualitative perspective. He Xuefeng (2006) analyzed the momentum mechanism of village cadres and also distinguished the different role types of village cadres. Fan Bonai and Dai Yue (2007) analyzed the main problems and influencing factors of the team of village cadres and held that the abilities and qualities of village cadres in China had a large gap with the requirements of the development objectives of the new villages and that election, training, motivation and risk avoidance mechanism of village cadres should be set up and perfected. Song Yanfeng (2009) took 
advantage of the materials of the second national agricultural general investigation, made a statistics about the quality characteristics of village cadres in different regions, disclosed the regional differences of quality of village cadres and proposed policies and suggestions for improving their qualities and narrowing the regional differences.

There are not so many researches concerning competency of village cadres in China. Jiang Daokui (2009) took the village cadres of Hechuan District, Chongqing as the research object and constructed the competency model of grass roots village cadres, including three dimensions (knowledge dimension, skill dimension and quality dimension) and 26 characteristic factors of competency; based on this competency model, they have proposed the talent cultivation mechanism of village cadres. Zhang Haiyang (2011) took Shaanxi Province as the example and adopted expert consultation method, layer analysis method and questionnaire to construct a competency model with 21 competency characteristics such as honesty and self-discipline ability, service motive, problem solving ability and team leadership etc. Based on the actual conditions of different regions, some scholars have conducted research about the competency model of undergraduate village official. Qiu Qi (2010) took the undergraduate village office in Beijing as the research object and summarized the competency elements for them through multiple quantitative methods. Some scholars have also conducted related research of competency and proposed the competency models with reference value for different industries and fields.

\section{Research of Rural Development}

Issue of rural development is very broad, covering many aspects; scholars have attached great importance to scholars since 1960s (Tan Chongtai 1994). Domestic and foreign scholars have made in-depth research of it from the perspective of different disciplines, such as economics, sociology and politics. The representative rural development theories in China include imbalanced grow theory of Hirschman. A (1958), research of urban and rural integrated mode of McGee T.G (1989) etc. Based on the conditions of rural villages, domestic scholars have achieved abundant research fruits in many fields such as anti-poverty, urban and rural planning, rural citizenization, urbanization and rural labor transfer etc. This paper only selects some of the academic researches highly related to this research.

\subsection{Connotation of Rural Development}

Wen Tiejun (2006) holds that rural construction and development should not just emphasize the economic growth, but should be comprehensive and scientific. Material civilization, spiritual civilization and political civilization should all be embodied; basic living facilities such as road, water and electricity should be constructed well; village environment should be maintained clean; social cause construction such as education, culture and hygiene should also be strengthened; meanwhile, basic construction ability of agriculture such as farmland, water and electricity, science and technology should also be strengthened. He also emphasized to boost the system construction centered on villager autonomy.

\subsection{Research of Influencing Factors of Rural Development}

Rural development is a complicated system issue, covering rural economic growth, improvement of life quality of villagers, progress of rural civilization and improvement of democratic awareness level. Villages in China are vast and broad, hence reasons for development differences of rural regions are also multifaceted.

The ultimate factor that influences rural economic development is the gap of ideology in different rural regions. The objective factor is the natural resource and the external factor is the difference of economic policy. China is one of the countries with the largest regional differences in natural resources and the most regional ecological types; the agricultural region can be divided into 
nine regions. The eastern region has less cultivated land for per person and less land, but it has abundant water and heat resources, more suitable for crops and forest crops. The middle region is at the humid and mid-humid temperate and subtropical zone and is the main body of domestic culture; however, it has less cultivated land for per person as well as less agricultural resources. Compared with the middle and eastern region, the western region has worse natural conditions and less resources, which restricts the development of agriculture. Especially the northwestern regions are dry, lacking in water and has weaker ecological environment; the southwestern region has more mountains, water and sloping fields with less cultivable regions and less cultivated land for per person, thus restricting the development of agriculture. Researchers of many scholars show (Liu Hui 2002, Gao Shengwang 2004) that the natural resources of village are its important influencing factor and also the uncontrollable factor. But such factor is natural and external; it is not the ultimate restrictive factor that influences rural development. Means such as scientific input can be used to reduce its restriction.

Geographical location reflects the status of this region in the total pattern of economic development of China and the spatial relation between market and other regions, which will have direct or indirect influence on the regional development. From the perspective of locational conditions, due to the abundant coastline resources and convenient transportation, which have smaller restrictions to economic development, eastern coastal areas have low transportation cost and unique import and export advantages. Locational and transportation conditions also directly influence the intensity of foreign investment. Injection of foreign investment is the important momentum for social and economic opening up of villages in coastal areas, which boosts the development of rural economy in coastal areas. Due to the restrictions of geographical location, the vast western villages cannot well attract the foreign investment, thus constraining the economic and social development (Liu Hui 2002).

\section{Research of Relation between Village Cadres and Rural Development}

Researches of many scholars show that village cadres play important roles in the social, political and economic development of villages. Village cadres are the leaders for villagers to get rich, the promoters of agricultural techniques and safeguards of rural society. The responsibility and work ability of village cadres can directly influence the rural development. 'Double training' practice in many villages and phenomenon that 'the capable elites govern the villages' has been more and more common, so some researches concerning relations between village cadres and rural development are also included in the researches of rural able men and elites. Liu Yang (2009) divides rural elites through system and holds that village cadres belong to the elites within the system. Rural elites have played important roles in rural governance; interaction among elites leads to the rural governance appearance to a great extent. Kuang Zongren and Yang Ping (2004) hold that rural elites are the important powers of rural development and their main roles include: vanguard model, organization and leadership, management, technical service and thinking appealing etc. The representative viewpoints of scholars are discussed in the following two influences of village cadres on rural development.

\subsection{Influence on Economic Development}

Gao Mengtao and Bi Lanlan (2009) took advantage of the micro panel data of 351 villages from 2003 to 2006, analyzed and researched the influence of knowledgeable and young village cadres on rural development. The following conclusions have been drawn: first of all, high knowledge level of village cadres can obviously boost the per capita income of the villagers, but does not reduce the poverty ratio. Second, the younger the village cadres are, the more obvious it is to reduce the poverty ratio of villages; however, the young age of village cadres has reversed influence on the 
average income of villagers; village cadres that are young and knowledge do not have obvious influence on the income of villagers, but it can obvious reduce the poverty ratio. Third, village cadres must well combine their experience with knowledge level so as to increase the per capita income of villagers and reduce the poverty ratio. Cao Xiaoheng and He Xiangbo (2008) analyzed the phenomenon of 'economic elites' among village cadres; they hold that 'economic elites' have certain payment ability and basic qualities, therefore if they act as the village cadres, on one hand, it can improve the quality structure of village cadres and increase the potential ability of basic organizations to develop economy; on the other hand, due to their strong social abilities, they can help invite investment for their villagers, thus acting as the bridge.

\subsection{Influence on Social Development}

The social 'atomized' tendency of villages has made the cooperative abilities of villagers weaker and weaker. Village cadres with strong leadership can exert their leading role and well organize the villagers through developing cooperation. Therefore, village cadres are the important organization resources of rural society in China. Zheng Yanghe (2009) studies the rural elites and found that on one hand, rural elites have become the leaders due to their strong organization and coordination abilities, influence and appealing forces and also protection of their own benefits; on the other hand, due to the special relationships in villages, village elites have become the advocates and maintainers of morals and standards in the rural society. Therefore, rural elites have played irreplaceable roles in the construction of rural civilization. Through field exploration and research of Huajiu Village, Xinanshan District, Qionglai City, Sichuan, Wu Peixian (2009) concluded that rural elites have boosted the development of the rural society as the promoter of the public cause of villagers, integrator of the rural society, demonstrator of morals and standards as well as maintainer of rural stability. Wang Liaowei (2008) researched the influence of village cadres on the rural cultural development. Through actual investigation of villages in the central Shaanxi plain, he found that temple fair is common in both the villages with good economic conditions and the common ones, which has become a tradition. The analysis holds that village cadres hold the indifferent attitudes towards the traditional personal culture, such as paper cutting and clay sculpture; however, for some public traditional cultures, such as temple fair, sacrifice and family tree, they will actively attend and organize the activities so as to gain the social incomes. These traditional public cultural activities are helpful for villagers to strengthen the idea of collectivism.

\section{Limitations and Enlightenment of Existing Researches}

(1) Related issues such as the qualities of village cadres and talent team construction have attracted attention of many scholars; more researches are done from the qualitative perspective. There are not many researches directly related to competency of village cadres. Most of the existing researches based on competency are targeted at undergraduate village officials, who are the minority of village cadre team; they are of strong homogeneity and the competency characteristics model is not universally used. Therefore, to construct the competency characteristics model of common rural cadres study and analyze the competency and influencing factors is of certain realistic significance and application value.

(2) At present, there are abundant measure researches concerning the rural development level. Scholars have constructed the index system of rural development based on different research perspectives; however, most of these researches are regional macro ones and lack the micro researches from the perspective of village. To gain the first-hand data of village development is of more realistic significance to research of rural development.

(3) Many scholars have been aware that village cadres play very important role in the rural development, such as the leaders for villagers to get rich, the promoters of agricultural techniques 
and safeguards of rural society. However, it is difficult to gain the first-hand statistical materials of village cadres who live in a relatively scattered way; there are no suitable starting points of research and scales to deepen and divide the demonstrative researches. Therefore, scholars have only given conceptual illustrations of the roles that village cadres play in the process of rural development; they have not had in-depth discussion nor systematic demonstrative research of the influence of village cadres' personal abilities and features on the rural development. Therefore, this field remains to be further tapped.

\section{References}

1. McClelland, D.C.1973.Testing for Competence Rather than for Intelligence. American Psychologist, 28(1):1-14.

2. Spencer L.M, and Spencer , S.M.1993. Competence at work: Models for Superior

Performance . John Wiley \& Sons, Inc, (17) : 18-24

3. Li Mingfei, Lu Xiaojun. 2004. Research on the construction of competency model and competency model. Journal of Dalian University of Technology (social sciences), 25 (1) : 28-32.

4. Boyatzis R.E.1982. The Competent Management: A Model for Effective Performance. New York: John Wiley \& Sons, Inc. (6): 26-32.

5.Cristina, M.B., \&Stewart, L.T.2004. Understanding of global leadership competency exploratory study.Journal of American Academy of Business, 11(8):881-884.

6. Wang Chongming. 2002. Analysis of managerial competency: the test of structural equation model. Psychological Science, 25 (1) : 513-516.

7. Wei Jun, Zhang De. 2005. Research on the competency model of domestic commercial bank account manager. Nankai Business Review, 8 (6) : 4-8.

8. Liu Guosheng, Zeng Zhenxiang. 2009. Research on competency model of principals in primary and secondary schools. Contemporary Educational Science, (22) : 54-56.

9. Chen Yansong. 2010. Constructing the competency model of College Counselors: An Empirical Study. Higher Education Research, 31 (4) :84-89.

10. Liu Wenkai, Hu Tongze. 2001. Research on the construction of the competency model of farmers' professional cooperatives leaders. Guangdong Agricultural Sciences, (1) : 242-244.

11. Hirschman.A.1958. Strategy of Economic Development. Yale University Press.

12. Mcgee T. G.1989.New Regions of Emerging Rural-Urban Mix in Asia: Implications for National and Regional Policy. Seminar on Emerging Urban-Rural Linkage,Bangkok:August:16-19.

13. Liu Hui. (2002). Study on the regional disparities of rural development in China. Geography and Geo-Information Science, 18(4),71-75.

14. Gao Wangsheng. 2004. Strategy of regional agricultural coordinated development in China. Beijing: China Agricultural University press.

15. Zheng, Y.H. (2009). On the cultivation of village elite and the construction of rural community culture: from the perspective of authority and order. Journal of Ningbo University (Liberal Arts Edition), 22 (3), 112-116. 